leading dimensions and weights, and such data is then used to show how the performance of an aeroplane may be calculated. The calculation involves the use of aerodynamical data already described, and also means of estimating the performance of propellers. The usual theory of propeller design is given, and although this now appears to be in need of improvement, the results obtained by its use have been of very great value. In addition to the calculations relating to equilibrium a chapter is included on the question of stability.

The book closes with a short description and discussion of aero-engines, and the whole appears to be very sound. The impression is left, however, that in the attempt to be concise too little assistance has been given to the reader. Like the book on aero-engines, by the same publisher, the production is excellent, the illustrations being particularly clear.

\section{THE VISIBILITY OF DISTANT OBJECTS IN WARFARE.}

THE long range of weapons employed in modern warfare has given importance to the study of the appearance of distant objects. A constant contest is taking place between the observer trying to locate the position and numbers of the enemy, and the observer who endeavours by all possible means to conceal these factors.

Generally speaking, an object becomes indistinguishable when its brightness and colour are identical with its surroundings. For this reason such colours as grey and khaki, which blend well with the surroundings, are preferred for modern uniforms. Yet their effectiveness in this respect depends on the nature of the ground over which troops are moving. Khaki is doubtless difficult to distinguish amidst sandy wastes; grey or green might be better against grass or foliage. Of all colours, red is the most conspicuous at a distance. Not only is it the colour which presents the most vivid contrast with the ordinary background, but there appear to be certain physiological factors which accentuate this impression. For example, it is well known that the central region of the eye (which is mainly used for the observation of distant objects) is highly sensitive to the red end of the spectrum and correspondingly insensitive to blue and green. It has also been alleged that, owing to the eye lens not being achromatic, most people find it difficult to focus distant blue and violet light; and that such objects readily merge in the landscape because their outlines are hazy and blurred. Skilful gardeners in designing a flower-bed arrange the blue and lilac flowers in the foreground when possible, and rely on vivid red and orange blooms for a distant effect.

It is known, however, that in a dim light the conditions obtaining in full daylight do not apply. In a feeble illumination the eye becomes more or less colour-blind and is highly insensitive to red, which appears dead black, whereas green and blue objects appear an uncanny grey. A party of men in grey-green uniforms advancing across a grass field in twilight would therefore be extremely difficult to detect.

All this suggests that the problem of selecting an inconspicuous uniform is a complicated one, especially when it is borne in mind that it is also important that bodies of men, besides being inconspicuous to the enemy, should be clearly visible to their own side. It has been suggested that this condition might be secured by differentiation in the colouring of the front and back of the uniform.

It is interesting to observe that on several occasions during the present war scouts have taken special steps to accommodate the colour of their clothing to the surroundings. For example, it is stated that the Germans provided some of their men with white uniforms in order to match the snow in the Polish campaign, and that the Turkish snipers in Gallipoli painted their hands and faces green so as to be indistinguishable amidst foliage.

It is clearly more difficult to secure resemblance to surfaces which are constantly changing, such as the sky and the sea. But there is a second principle which can also be used to secure inconspicuousness in these circumstances, namely, what may be termed the "patchwork" principle. This is based on the experience that the outlines of an object may be rendered difficult to distinguish by breaking up its surface with stripes and patches. This method has been applied to aircraft and hydroplanes, and to forts and temporary defences of various kinds. Besides painting the hulls and funnels of warships a slaty-blue or "battle-grey," experiments have been made with mottled patches of black and irregular serpentine black lines painted on a grey background. Some experiments in this direction recently carried out in the United States Navy are said to have been very successful, and it may be only a question of time before Dreadnoughts are rendered practically invisible at the long range of modern sea-battles.

A combination of patchwork and imitation of surroundings may also be applied with good results in order to conceal aerodromes and similar objects. For example, if the adjacent ground is cleared and the grass is scraped away at intervals, leaving bare patches, and if the aerodrome itself is painted a patchwork of brown and green, identification from above becomes very difficult. Yet another instance is furnished by the recent correspondence in the Times regarding the colour of sandbags. It is stated that the Germans insert black sandbags at intervals among those of lighter tint. An officer at the front wrote:-“. .. It was the first thing I noticed about the German trenches. Their patchwork device made it impossible to spy their loopholes, whereas ours take a long time to build and then are easily seen."

A device such as this, which would apparently save a considerable number of lives in a long campaign, is well worth attention.

There remains one other possible device for concealing objects which, although difficult to

NO. 2396, VOL. 96] 
apply, is probably the most perfect of all when realisable. This is to make use of mirror or semimirror surfaces which reflect their surroundings and thus automatically imitate them. Such a device would be applicable in any surroundings.

The chief instance known to the author of the use of this method is afforded by the latest Zeppelins, which are reported to have a coating of bright aluminium powder, which reflects the sky and makes the vessel very difficult to detect at any considerable height. For aircraft flying at a height the problem of concealment is a particularly difficult one, as whatever pigment is adopted the framework is seen silhouetted against the bright sky. It is possible that by making use of reflecting surfaces, in addition to the other devices mentioned, this contrast could be considerably lessened. If to a noiseless engine could be added the quality of practical invisibility, aircraft would become very much more dangerous offensive machines than at present.

Such problems as those mentioned above seem to deserve careful scientific study. Methods of concealment may do much to save the lives of combatants. Moreover, the utility of all vessels employed for scouting purposes, whether aircraft, motors, or submarines, depends to a great extent on their escaping detection. It is therefore surely well worth while to follow up any train of research which offers any promise of approaching invisibility in the future.

J. S. D.

\section{PROF. W. H. H. HUDSON.}

$\mathrm{W}^{\mathrm{E}}$ greatly regret to record the death, on September 2 I, of Prof. W. H. H. Hudson, at the age of seventy-six years. Born in London, he graduated as Third Wrangler in $\mathbf{1 8 6} \mathbf{1}$. He was then fellow and lecturer of St. John's College until 1882 , when he was appointed professor of mathematics at King's College, London. There, and also as professor of mathematics at Queen's College, Harley Street, he worked until his retirement about twelve years ago.

It is as a lecturer, and as a constructive reformer of the teaching of elementary mathematics that Prof. Hudson's vigorous influence will long be felt. Of his numerous pupils many became teachers, and the improvements in modern methods of teaching must be largely due to his inspiration. He edited Barnard Smith's "Arithmetic," published notes on dynamics, gave various addresses on the teaching of elementary mathematics, contributed to the mathematics of meteorology with a theory of anemoids, and did much to promote order and economy in the study of mathematics by adding to its vocabulary terms now generally found useful. He was an active member of the conference which reported to the London County Council on the teaching of arithmetic; of the councils of the London Mathematical Society and of the Mathematical Association; and of the governing body of Newnham College, in the welfare of which (as of the education of women generally) he was warmly interested.

$$
\text { NO. 2396, VOL. 96] }
$$

Prof. Hudson's principles received remarkable vindication in the record of his family. By the tragic death on Snowdon, in 1904, of his only son, Cambridge lost one of its most brilliant Senior Wranglers, and perhaps the most widely accomplished. The researches of Ronald Hudson in Kummer's "Quartic Surface," published posthumously, placed him in the front rank of geometers. The three surviving daughters of Prof. Hudson have all distinguished themselves as mathematicians.

Few men intimate with the austerities of the most difficult of subjects can have made a wider circle of personal friends than did Prof. Hudson. He had the gift of humour and sympathy which endeared him to all those he taught. He enjoyed travel and recreation to the end of his days, and within the boundaries of mathematical study he knew how to find both.

\section{NOTES}

The Rev. Dr. E. W. Barnes, fellow and tutor of Trinity College, Cambridge, has been appointed to the mastership of the Temple. Dr. Barnes is in his forty-first year, and had a brilliant career at Cambridge. He went up to the University as a scholar of Trinity College, and in 1896 was bracketed second Wrangler. A year later he took a first class in the first division of the Mathematical Tripos, part ii. and was first Smith's prizeman in 1898 , besides being president of the Union. He was elected a fellow of his college in the same year, and was an instructor at the Royal Military Academy, Woolwich, in 1898-99. $\mathrm{He}$ is the author of various memoirs and papers on Gamma functions, integral functions, linear difference equations, and related mathematical subjects.

THE Victoria Cross is given for conspicuous courage in the face of the enemy: and, if we want a good example of such courage, we have it in the English nurse, at the American Hospital at Neuilly, who inoculated herself with a pure culture of the bacilli of gas-gangrene, that she might help the discovery of the best treatment of that disease. We rejoice that she now is out of danger of death The annals of medicine record many similar instances of selfdevotion, and doubtless there are others which have gone unrecorded. They have not always been of use to mankind: John Hunter, for example. inoculated himself with the virus of one of the venereal diseases, but drew a wrong conclusion fron the results of the experiment. The amazing self-experiments with yellow fever, in Camp Lazear, were happily not in vain. The protective treatments against cholera, plague, and typhoid fever were of course, well tested by their discoverers on themselves before they were put to national uses. A good essay is waiting to be written on the whole subject of self-experimentation. Lord Moulton, in his evidence before the Royal Commission on Vivisection, discusses the ethics of it, and he does that very well. But formal ethics scarcely touch the case; the self-experimenter, in the presence of the enemy, the germs, the havoc they work on men, women, and children, "sees red," and behaves 